\title{
Final Report for ARM Project Measuring 4-D Water Vapor Fields with GPS
}

\section{Summary}

Water vapor is a primary element in the Earth's climate system. Atmospheric water vapor is central to cloud processes, radiation transfer, and the hydrological cycle. Using funding from Department of Energy (DOE) grant DE-FG03-02ER63327, the University Corporation for Atmospheric Research (UCAR) developed new observational techniques to measure atmospheric water vapor and applied these techniques to measure four dimensional water vapor fields throughout the United States Southern Great Plains region. This report summarizes the development of a new observation from ground based Global Positioning System (GPS) stations called Slant Water Vapor (SW) and it's utilization in retrieving four dimensional water vapor fields. The SW observation represents the integrated amount of water vapor between a GPS station and a transmitting satellite. SW observations provide improved temporal and spatial sampling of the atmosphere when compared to column-integrated quantities such as preciptitable water vapor (PW). Under funding from the DOE Atmospheric Radiation Measurement (ARM) program, GPS networks in the Southern Great Plains (SGP) region were deployed to retrieve SW to improve the characterization of water vapor throughout the region. These observations were used to estimate four dimensional water vapor fields using tomographic approaches and through assimilation into the MM5 numerical weather model. 


\section{Network Installation and Operation}

Two networks of GPS stations have been deployed in the SGP region primarily through collaborations between UCAR, the University of Oklahoma, and the ARM program. The existence of these networks for atmospheric applications makes the area unique in the station density and its focus towards atmospheric science. The data collected here offer ARM investigators the ability to sample the atmosphere on scales of a few kilometers to 100 's of kilometers. The first network consists of 24 single frequency GPS stations deployed within a 40 square kilometer area around the ARM Central Facility (CF). In order to cost effectively deploy 24 GPS stations at sites without power and communications infrastructure, UCAR developed a GPS system that incorporated a low cost, single frequency GPS OEM board with a $900 \mathrm{MHz}$ radiomodem transceiver so that data could continously be streamed to a central computer. These systems are powered by solar power with a battery backup and are significantly cheaper than typical GPS systems used for atmospheric sensing. The price of the GPS receiver and antenna used in this system is less than $\$ 500$. This compares to a typical cost of between $\$ 5,000$ 10,000 for other receivers used in atmospheric sensing. These systems are extremely robust, withstanding storms and vandalism, and operate with only a modest amount of monitoring. Each station is installed on private property using a land lease agreement with UCAR. The leases come up for renewal each August. This so-called micro-network is effectively a single sensor spanning $40 \mathrm{~km}^{2}$. The observations from this network are combined with a profile of water vapor from the central facility and three-dimensional water vapor fields are now computed routinely. The second network of stations is part of the larger SuomiNET network (Ware, et al., 2000). Fifteen GPS stations are installed at 
ARM facilities within the SGP region. They provide data that are analyzed to produce zenith integrated precipitable water (PW) measurements. The ARM program now retrieves these PW products and archives them in the ARM external data center. Currently there are two products available. The first product contains PW amounts from stations within the continental United States, including the SGP region. The second product is a global collection of PW measurements.

\section{Measurement of Slant Water Vapor}

The measurement of the integral amount of water vapor along the slant path between a GPS receiver and transmitting GPS satellite has been termed Slant Water Vapor (SW). In contrast to $\mathrm{PW}$ that represents the vertically integrated amount of water vapor above a station and assumes azimuthal homogeneity, SW captures the azimuthal variability of water vapor around a station. With 6 to 12 GPS satellites visible from any location on Earth at all times, SW offers a more detailed picture of the distribution of water vapor than a single PW value. The measurement of SW has been summarized through a series of papers (Ware, et al., 1997, Alber et al., 2000, Braun, et al., 2001, and Braun, et al., 2003). These studies compare GPS SW observations to those collected with a microwave water vapor radiometer (MWR). As with many new observing systems, the technique of measuring SW has been a heated topic of debate. To assess the accuracy and robustness of SW retrieval methods, we conducted an observing system simulation experiment to evaluate the technique. These results are available in Braun and Ha (2007). In this study, the high-resolution MM5 model simulation was used to create simulated observations. These simulated observations were then analyzed using standard SW retrieval techniques developed as part of our ARM work. Comparing the retrieved results to the known 
atmospheric conditions ("truth") from the model, we have been able to show that GPS $\mathrm{SW}$ is indeed a robust observation and that it provides an improved technique for monitoring the distribution of atmospheric water vapor, especially under rapidly changing weather conditions.

\section{Water Vapor Tomography}

The combination of SW observations from a network of GPS stations to resolve the three dimensional distribution of water vapor above the network region is an application of tomographic theory - widely used in such diverse fields as medicine and seismology. This technique has been applied to the data collected with the micro-network of GPS stations around the central facility. Initial results from these solutions relied solely on GPS observations and suffered from poor retrieval of the vertical structure. Two improvements in this technique have been implemented due to ARM funding. The first is the incorporation of external profile information into the estimation. For the micronetwork of stations, the vertical profile of water vapor density from the ARM Raman Lidar is now used to resolve the vertical structure while the GPS observations resolve the horizontal structure as well as the vertical variability of water vapor within the tomography region. The second is a modification of the software that enables it to work as a sequential batch estimator. This allows the tomographic field from the most recent solution to be used as the apriori field in the subsequent solution, providing a more consistent estimate over time, which improves the tracking of water vapor features as they move through the analysis region.

Tomography solutions over a larger domain were obtained using data collected during the International $\mathrm{H}_{2} \mathrm{O}$ Project (IHOP) in May and June of 2002 (Braun, 2004). The 
deployment of seven additional stations within $100 \mathrm{~km}$ of the central facility allowed for the expansion of the tomography region to an area of about $100 \times 180$ kilometers. The solutions computed during this period utilized the radiosonde observations from the central facility to assist in the recovery of the vertical profile. Temporal and spatial interpolation between radiosonde launches within the $18,000 \mathrm{~km}^{2}$ region was maintained and adjusted solely with the GPS SW observations through the implementation of the sequential batch estimator. These results are described in detail in the Braun (2004) Ph.D. dissertation.

\section{Assimilation of SW into a Numerical Weather Prediction Model}

To assess the impact of line-of-sight GPS observations on the determination of the four-dimensional variation of the atmospheric water vapor field and on short term forecasting accuracy, Ha et al. (2003) conduted an Observing System Simulation Experiement (OSSE) study. In this OSSE study, we compared the model forecasts without GPS, with GPS PW and with GPS SW assimilation. We found that four dimensional variation assimilation of slant wet delay in the NCAR/Penn State MM5 model improves model prediction of the intensity and timing of the squall line, and the distribution and total rain that occurred during the storm. While weather is not the focus of ARM, these results are strongly relevant to the ARM program because they illustrate the importance of detailed water vapor distribution observations for accurate analysis and simulation of clouds and cloud systems. The accurate depiction of water vapor over scales smaller than GCM model resolution is important for multiscale modeling studies, or "super-parameterizations". 


\section{Publications related to DOE Funding}

Alber, C., R. Ware, C. Rocken, J. Braun, 2000: Obtaining single path phase delays from GPS double differences. Geophys. Res. Lett., 27, 2661-2664.

Braun, J. J., C. Rocken, et al. (2001). "Validation of single slant water vapor measurements with GPS." Radio Science 36: 459-472.

Braun, J. J., C. Rocken, et al. (2003). "Comparisons of line-of-sight water vapor observations using the global positioning system and a pointing microwave radiometer." Journal of Atmospheric and Oceanic Technology 20: 606-612.

Braun, J. J., 2004: Remote Sensing of Atmospheric Water Vapor with the Global Positioning System, Department of Aerospace Engineering Sciences, University of Colorado, $158 \mathrm{p}$.

Braun, J. J. and S.-Y. Ha, 2007: An Analysis of Errors Associated with GPS Slant Retrieval Techniques in a Simulation Study. Journal of Atmospheric and Oceanic Technology, Submitted.

Ha, S.-Y., Y.-H. Kuo, Y.-R. Guo, and G.-H. Lim, 2002: Variational assimilation of slantpath set delay measurements from a hypothetical ground-based GPS network: Part I - Comparison with precipitable water assimilation. Mon. Wea. Rev., 131, 2635-2655.

Ha, S.-Y., Y.-H. Kuo, Y.-R. Guo, C. Rocken, and T. Van Hove, 2002: Comparison of GPS slant wet delay measurements with model simulations during the passage of a squall line. Geophys. Res. Lett., 29, 2113, doi: 10.1029/2002GL015891.

Rocken, C., S. Sokolovskiy, et al. (2001). "Improved mapping of tropospheric delays." Journal of Atmospheric and Oceanic Technology 18(7): 1205-1213. 


\section{Appendix 2: Presentations and Extended Abstracts}

\section{During Latest Funding Cycle}

Braun, J., T. Van Hove, S. Y. Ha, C. Rocken, 2002: GPS water vapor projects within the ARM Southern Great Plains region. Proceedings of the Twelfth Atmospheric

Radiation Measurement (ARM) Science Team Meeting, St. Petersburg, FL April 8$12,2002$.

Braun, J., and C. Rocken, 2003: Slant water vapor observations in the United States Southern Great Plains. Proc. International Workshop on GPS meteorology: Groundbased and Space-borne applications, 14-17 January, Tsukuba, Japan (INVITED).

Braun, J., and C. Rocken, 2003: Water vapor tomography within the planetary boundary layer using GPS. Proc. International Workshop on GPS meteorology: Ground-based and Space-borne applications, January 14-17, Tsukuba, Japan (INVITED).

Braun, J., T. Van Hove, and C. Rocken, 2003: Using the Global Positioning System to improve the characterization of water vapor in the Southern Great Plains.

Proceedings of the Thirteenth Atmospheric Radiation Measurement (ARM) Science Team Meeting, Broomfield, CO March 31- April 4, 2003.

Braun, J., Y.-F. Xie, 2003: Observed convergence of water vapor prior to and during the June 12-13 2002 Northern Oklahoma storm using the Global Positioning System. 31st International Conference on Radar Meteorology, Seattle, WA, 2003.

Braun, J., S.-Y. Ha, C. Rocken, and Y.-H. Kuo, 2003: Assessing the accuracy of slant path measurements using a high resolution numerical weather model. $A G U 2003$ Fall meeting. 8-12, December, San Francisco, CA.

Braun, J., C. Rocken, and Y.-H. Kuo, 2004: Observed water vapor fields during the International $\mathrm{H}_{2} \mathrm{O}$ project using GPS. Proceedings of the Fourteenth Atmospheric Radiation Measurement (ARM) Science Team Meeting, Albuquerque, NM March 22- March 26, 2004.

Braun, J., S.-Y. Ha, C. Rocken, and Y.-H. Kuo, 2004: An evaluation of slant water vapor using a high resolution numerical weather model. Proceedings of the Fourteenth Atmospheric Radiation Measurement (ARM) Science Team Meeting, Albuquerque, NM March 22- March 26, 2004.

Ha, S.-Y., J. Braun, Y.-H. Kuo, and C. Rocken, 2003: An error analysis of ground-based GPS slant-path residuals in a simulation study. AGU 2003 Fall meeting. 8-12, December, San Francisco, CA.

Ha, S.-H., and Y.-H. Kuo, 2003: Variational Assimilation of ground-based GPS slant wet 
delays aind its impact on short-range weather prediction, Proceedings of the Thirteenth Atmospheric Radiation Measurement (ARM) Science Team Meeting, Broomfield, CO March 31- April 4, 2003.

Ha, S.-Y., Y.-H. Kuo, and G.-H. Lim, 2003: The impact of ground-based GPS slant-path wet delay measurements on short-range prediction of a prefrontal squall line. Proc. The 83rd AMS Annual Meeting: Symposium on Observing and Understanding the Variability of Water in Weather and Climate, 9-13, Februray, Long Beach, CA.

Ha, S.-Y, 2003: Variational assimilation of ground-based GPS slant wet delays and its impact on short-range numerical weather prediction. MMM seminar, $30 \mathrm{Jan}$, Boulder, $C O$.

Ha, S.-Y. and Y.-H. Kuo, 2003: Assimilation of GPS slant wet delay: Impact of observing network design. Proc. International Workshop on GPS meteorology: Ground-based and Space-borne applications, 14-17 January, Tsukuba, Japan.

Ha, S.-Y., Y.-H. Kuo, Y.-R. Guo, and G.-H. Lim, 2002: Assimilation of ground-based GPS slant-path water vapor measurements and its impact on short-range prediction of a pre-frontal squall line: An OSSE study. Proc. Third US-KOREA Joint Workshop on Storm Scale and Mesoscale Weather Analysis and Prediction, 82-86, Boulder, CO.

Rocken, C., T. Van Hove, S.-Y. Ha, J. Braun, D. Hunt, R. Ware, Y.-H. Kuo, 2002: Recent ground based GPS meteorology developments for SuomiNet. Proc. Of COST Action 716 Workshop: Exploitation of Ground-Based GPS for Meteorology, January 28-29, GeoForschungsZentrum, Potsdam, Germany.

Rocken, C., J. Braun, T. Van Hove, J. Johnson, Y.-H. Kuo, 2003: Developments in ground based GPS meteorology. Proc. International Workshop on GPS meteorology: Ground-based and Space-borne applications, 14-17 January, Tsukuba, Japan (INVITED).

Schmid, B., J. Redemann, J. A. Eilers, D. M. McIntosh, K. Longo, P. B. Russell, J. M. Livingston, J. Braun and C. Rocken, 2001: Sunphotometric measurement of columnar $\mathrm{H}_{2} \mathrm{O}$ and aerosol optical depth during the 3rd water vapor IOP in Fall 2000 at the SGP ARM site. Proceedings of the Eleventh Atmospheric Radiation Measurement (ARM) Science Team Meeting, Atlanta, GA, March 19-23, 2001.

Van Hove, T., J. C. Liljegren, C. Rocken, J. Braun, 2004: Using GFS weather model to reduce diurnal differences between GPS PW and ARM MWR PWV. Proceedings of the Fourteenth Atmospheric Radiation Measurement (ARM) Science Team Meeting, Albuquerque, NM March 22- March 26, 2004. 


\section{Project URLS}

http://www.cosmic.ucar.edu/ braunj

http://www.suominet.ucar.edu/ 